\title{
MÉDICOS BRASILEIROS: A FORMAÇÃO, A PROFISSÃO E O DESAFIO DE TRABALHAR DURANTE A PANDEMIA DO COVID-19
}

\author{
LOS MÉDICOS BRASILEÑOS: LA FORMACIÓN, LA PROFESIÓN Y EL RETO DE \\ TRABAJAR DURANTE LA PANDEMIA DE COVID-19
}

\author{
BRAZILIAN PHYSICIANS: THE TRAINING, THE PROFESSION AND THE \\ CHALLENGE OF WORKING DURING THE COVID-I9 PANDEMIC
}

\author{
Neide Liamar Rabelo de Souza ${ }^{1}$ \\ Aparecida Abreu Ferreira da Silva ${ }^{2}$ \\ Maria Aparecida Santos e Campos ${ }^{3}$
}

RESUMO: Estudo embasado na análise bibliográfica e documental sobre a formação universitária em medicina, a empregabilidade dos médicos em tempos de normalidade e em condições excepcionais como a pandemia causada pelo Covid-19 e suas variantes. A abordagem teórica para a investigação está na Teoria do Capital Humano (TCH), que tem como princípio o investimento em educação e o esperado retorno por meio da remuneração compatível com uma formação superior até a transferência para a aposentadoria. Compreende o aprimoramento de aptidões e habilidades dos indivíduos, esperando produtividade e, consequentemente, crescimento econômico ao país. A empregabilidade dos médicos e a condução do trabalho em tempos de normalidade e em situação de exceção, será analisada sob a perspectiva da Teoria do Contrato Social (TCS), considerando o compromisso assumido pelos médicos, no juramento de Hipócrates ao concluírem o bacharelado, referencial para o compromisso ético de garantir a saúde e sobrevivência dos indivíduos. A TCS surgiu para vincular a finalidade do poder público assistir à parcela hipossuficiente da população. O Estado é o responsável direto ou indiretamente pela formação acadêmica e empregabilidade dos nacionais, no caso em tela, os médicos, seja na

\footnotetext{
${ }^{I}$ Doutoranda em Educação, pela Universidad Internacional Iberoamericana (UNINI) - México. Linha de pesquisa: Economia da Educação. Mestra acadêmica em Direito (2010), pela Universidade Católica de Brasília. Linha de pesquisa: Direito Econômico Internacional. Especializações lato sensu: Indicadores Científicos e Tecnológicos (1989) - Conselho Nacional de Desenvolvimento Científico e Tecnológico (CNPq); Recursos Humanos (2017) - Instituto Educacional de Ensino Superior Brasileiro (IDESB); Gestão Cultural: cultura, desenvolvimento e mercado (2018) - pelo Centro Universitário SENAC. Antropologia (2018) - Universidade Cândido Mendes; Direito Imobiliário (2019) - Faculdade Única de Ipatinga.

https://orcid.org/oooo-ooo2-8320-6105. http://lattes.cnpq.br/5885421247777087.E-mail: liamarrs@gmail.com

${ }^{2}$ Doutoranda em Educação, pela Universidad Internacional Iberoamericana (UNINI) - México linha de pesquisa: Análise dos registros verbais sobre bullying e seu efeito no processo socioeducativo dos alunos do Io ciclo do Ensino Fundamental de escolas públicas de Niterói-RJ. Mestra em Ciências em Engenharia de Transportes (2010), pela Universidade Federal do Rio de Janeiro (UFRJ). Linha de pesquisa: Utilização do desenho como instrumento para análise da percepção de risco e medo no trânsito. Especializações lato sensu: em Recursos Humanos (20I5) - UNIRIO; Deficiência Intelectual (2015) - UNIRIO D - Graduação: Bel. em Psicologia (1990) - Faculdades Integradas Maria Thereza de instituições públicas escolares de Niterói. https://orcid.org/oooo-0003-2748-6015 http://lattes.cnpq.br/3276258228936508 E-mail: cida.abreu@gmail.com.

${ }^{3}$ PHD em Educação Física. Mestre em Ciências da Educação. Pós-graduada lato sensu: Planejamento e Metodologia da Investigação Científica; Metodologia do Ensino Superior; Educação Física Escolar; Psicologia da Educação.

https://orcid.org/ooooooor17905438http://lattes.cnpq.br/1253652978692557.

mariaaparecidasantosecampos@gmail.com. 
qualificação formativa, o número ideal de profissionais em cada ente federado e oferecimento de subsídios para sua efetiva atuação nos diferentes ambientes. Metodologia: pesquisa qualitativa e descritiva apoiada em revisão bibliográfica e documental. Objetivo: a formação acadêmica dos bacharéis em medicina, a empregabilidade e as condições para o desempenho da atividade, em especial, a partir de 12/3/2020, com a decretação, pela Organização Mundial de Saúde (OMS), da pandemia. Resultado: A categoria dos médicos continua cuidando da saúde de todos, mesmo sabedores que estão em meio a uma patologia altamente contagiosa, como a pressão psicológica pode desencadear problemas de saúde física e mental, mas seguem cumprindo o pacto social do bem comum.

Palavras-chave: Covid-ı. Pandemia. Médicos. Ações do Estado. Doenças profissionais.

RESUMEN: Este estudio se basa en el análisis bibliográfico y documental de la formación universitaria en medicina, la empleabilidad de los médicos en tiempos normales y en condiciones excepcionales como la pandemia causada por el Covid-19 y sus variantes. El enfoque teórico de la investigación se encuentra en la Teoría del Capital Humano (TCH), que tiene como princípio la inversión en educación y el retorno esperado a través de la remuneración compatible con una educación superior hasta el traslado a la jubilación. Comprende la mejora de las aptitudes y habilidades de los individuos, esperando la productividad y, en consecuencia, el crecimiento económico del país. La empleabilidad de los médicos y la realización del trabajo en tiempos de normalidad y en situaciones de excepción, serán analizados desde la perspectiva de la Teoría del Contrato Social (TCS), considerando el compromiso asumido por los médicos, en el Juramento Hipocrático al graduarse, una referência para el compromiso ético de garantizar la salud y la supervivencia de los individuos. El TCS surgió para vincular el propósito del poder público de asistir a la parte hiposuficiente de la población. El Estado es responsable, directa o indirectamente, de la formación académica y de la empleabilidad de los nacionales, en este caso, de los médicos, ya sea en la cualificación formativa, del número ideal de profesionales en cada entidad federada y del ofrecimiento de subvenciones para su desempeño efectivo en los distintos ámbitos. Metodología: Investigación cualitativa y descriptiva apoyada en la revisión bibliográfica y documental. Objetivo: la formación académica de los bachilleres en medicina, la empleabilidad y las condiciones para el desempeño de la actividad, en especial, a partir del 12/3/2020, con la decretación, por parte de la Organización Mundial de la Salud (OMS), de la pandemia. Resultados: La categoría de los médicos sigue cuidando la salud de todos, incluso sabiendo que están en medio de una patología altamente contagiosa, como la presión psicológica puede desencadenar problemas de salud física y mental, pero seguir cumpliendo el pacto social del bien común.

Palabras-clave: Covid-ı. Pandemia. Los doctores. Acciones del Estado. Enfermedades profesionales.

ABSTRACT: A study based on bibliographic and documentary analysis of university training in medicine, the employability of doctors in normal times and in exceptional conditions such as the pandemic caused by Covid-rg and its variants. The theoretical approach for the research is in the Theory of Human Capital (TCH), which has as its principle the investment in education and the expected return through remuneration 
compatible with a higher education until the transfer to retirement. It comprises the improvement of aptitudes and abilities of individuals, expecting productivity and, consequently, economic growth to the country. The employability of doctors and the conduction of the work in times of normality and in situations of exception, will be analyzed from the perspective of the Social Contract Theory (SCT), considering the commitment assumed by doctors, in the Hippocratic Oath upon graduating, a reference for the ethical commitment to guarantee the health and survival of individuals. The TCS arose to bind the purpose of the public power to assist the hyposufficient portion of the population. The State is directly or indirectly responsible for the academic training and employability of nationals, in this case, doctors, whether in the formative qualification, the ideal number of professionals in each federated entity and offering subsidies for their effective performance in different environments. Methodology: Qualitative and descriptive research supported by bibliographic and documentary review. Objective: the academic training of graduates in medicine, employability and conditions for the performance of the activity, in particular, from $12 / 3 / 2020$, with the decree, by the World Health Organization (WHO), of the pandemic. Results: The category of physicians continues to take care of everyone's health, even though they are aware that they are in the midst of a highly contagious pathology, as psychological pressure can trigger physical and mental health problems but continue to fulfill the social pact for the common good.

Keywords: Covid-ı. Pandemic. Doctors. State Actions. Professional diseases.

\section{INTRODUÇÃO}

A medicina é uma carreira almejada por muitos, porém conquistada por poucos, no entanto, os números são promissores, com os da publicação Demografia Médica no Brasil, outubro de 2020, o país contava com 357 escolas médicas entre instituições públicas e privadas, disponibilizando 37.823 vagas anuais para o ingresso no Io ano da graduação. $\mathrm{O}$ Censo da Educação Superior de 2020, com registros de 2019 (INEP, 2020), indicou que 187.710 estudantes estavam cursando o bacharelado do curso. É uma das oito carreiras mais disputadas no ranking de formação acadêmica (SCHEFFER et al., 2020, p. 95).

O Sistema de Seleção Unificada ( $\mathrm{SiSu}$ ) é a agregação informatizada do Ministério da Educação (MEC), em que instituições públicas de ensino superior oferecem vagas para candidatos participantes do Exame Nacional do Ensino Médio (ENEM). O acesso aos cursos de medicina em Instituições do Ensino Superior (IES) estatais, exigem dos estudantes dedicação exclusiva e empenho nos estudos, considerando a acirrada disputa para ingresso. Em 2020, a média para medicina foi de 780 pontos e em 2021, alcançou 813,40 (nota de corte mínimo 775,48, média 814,93 e a pontuação máxima possível de I.00o), o número de vagas foi de 4.340. É uma carreira de elevado prestígio, porém exige contínuos 
estudos para manter os conhecimentos; o retorno vem da capacidade de resguardar e/ou salvar vidas (MEC, 202I).

A valorização social decorre, desde a antiguidade, iniciada como magia e empirismo, a medicina tem sua evolução para a ciência, por volta do ano 2.648 a.C. no Egito, com uma nova visão, na interpretação natural da doença. Os registros históricos indicam o egípcio Imhotep $(2667$ - 2648 a.C.) como primeiro médico. Muitos anos depois o médico grego Hipócrates (46o a 377 a.C.), na tradição ocidental, é considerado o pai da medicina, devido ao legado ético e moral válido até hoje. A atividade dos médicos tem grande valia para a humanidade, pois sua função está diretamente ligada ao serviço da preservação do maior patrimônio natural: a vida (REZENDE, 2009, p. 2I).

Ao início da terceira década do século XXI, a população mundial se depara com um dos mais assustadores episódios relacionados a preservação da humanidade, a pandemia do Covid-ı9. Diante de um cenário de devastação, considerando a potência destrutiva do vírus. A disseminação do contágio, o desconhecimento no tratamento terapêutico e a falta de infraestrutura nos hospitais para o acolhimento dos doentes, é sugerida a decretação de lockdown no mundo. A população assustada, recolhe-se em seus domicílios, cabendo a poucos a exposição direta ao vírus, em um primeiro momento.

No centro do problema estavam os cientistas e profissionais da saúde: médicos, enfermeiros, técnicos e um imenso aparato de força humana, para o combate ao novo vírus, que inicialmente fora tratado de forma experimental, considerando o desconhecimento quanto a sua reação diante da oferta do tratamento. As medidas políticas adotadas, a dedicação exclusiva aos doentes, o afastamento da família, a incerteza na exploração terapêutica, o medo do contágio. A falta de infraestrutura instalada levou à necessidade da construção de hospitais de campanha levou todos os envolvidos com a manutenção da saúde coletiva à exaustão física e emocional; mas seguiram firmes, na luta incessante contra o coronavírus e pela existência humana.

Muitos trabalhadores da área de saúde foram contaminados pelo Covid-19, no entanto, tão logo se recuperaram voltaram para seus postos laborais com dedicação e empenho. Enquanto isso, nos laboratórios estavam incansavelmente ocupados pelos cientistas com dedicação obstinada na criação, desenvolvimento e testes de vacinas antídotos para esse mal que assola a sociedade, mudando a rotina sem aviso prévio. Depois 
de meses chegaram a cerca de cinco imunizantes com autorização emergencial para ser aplicada nas pessoas, o primeiro foi aplicado na Inglaterra, em 8/12/2020; mesmo assim, os aperfeiçoamentos e ajustes estão em curso.

O presente estudo abordará a carreira dos médicos com respaldo na Teoria do Capital Humano (TCH) de Schultz (1967, p. 13) cuja proposta consiste na qualificação da mão de obra por meio da Educação, um dos mais importantes meios para incremento da produtividade e, consequentemente, para o lucro. A instrução agrega valor à profissão que as pessoas escolhem para dedicar, podendo exercer seu ofício com fundamentação teórica e prática o que proporciona desempenho qualificado, com alta operosidade, indicando remuneração compatível com a especificidade dos bens ou serviços produzidos. Sabidamente, em momentos de desemprego, eles não menos afetados e costumam ter trabalho até se transferirem para a inatividade.

A teoria do Contrato Social ${ }^{4}$ será o subsídio utilizado para analisar as condições físicas e psicológicas da categoria dos médicos, com o advento da pandemia pelo Covid-i9. Esta teoria traz à reflexão filosófica que as partes envolvidas devem procurar mais do que o próprio benefício, devem visar o bem-estar da sociedade. Em estado de natureza os indivíduos vivem isolados e reina o medo; o que levam as pessoas a transferirem parte de suas liberdades a um terceiro (o soberano $=$ Estado) que deve cuidar da comunidade de uma forma indivisa, incentivar e fazer gestões para o compartilhamento dos mesmo bens, que possam desfrutar de vantagens recíprocas (FERREIRA et al., 2020, p. 362).

O objetivo desta pesquisa é verificar a empregabilidade dos médicos, a formação acadêmica dos bacharéis, a profissão e as condições de exercício da atividade, em especial nos anos de 2020-2I, quando o mundo foi surpreendido com a pandemia do Covid-r9, impactando no cotidiano de todos e, em especial dos profissionais de saúde.

\section{FORMAÇÃO ACADÊMICA EM MEDICINA NO BRASIL}

A história da carreira médica no Brasil conta com mais de 200 anos. A primeira faculdade surgiu em Salvador, Bahia em 18/2/1808, chamada de Escola de Cirurgia da Bahia, atualmente é a Faculdade de Medicina da Bahia (FAMEB), da Universidade

\footnotetext{
${ }^{4}$ Os filósofos contratualistas são: Thomas Hobbes, John Locke e Jean-Jacques Rousseau usaram uma metáfora que defendiam que o homem e o Estado devem fazer um acordo a fim de garantir a sobrevivência.
} 
Federal da Bahia (UFBA). No mesmo ano, em 5 de novembro, no Rio Janeiro, foi inaugurada a Escola de Anatomia, Medicina e Cirurgia, posteriormente renomeada como Faculdade de Medicina da Universidade Federal do Rio de Janeiro (FM-UFRJ).

No presente século, o bacharelado em ciências médicas é um dos mais extensos, com duração mínima de seis anos. As motivações podem ter várias origens, dentre elas: o encorajamento de salvar vidas, o status que a profissão traz, a possibilidade de ter uma carreira longeva, só para citar alguns estímulos que a carreira tem. Segundo as estatísticas da Escolas Médicas do Brasil (EMB), ao concluírem a graduação, via de regra, não ingressam no mercado de trabalho. Migram para a etapa da residência médica além de almejada é exigida para a prática das especialidades que envolvem as incumbências laborais. Etapa vinculada a formação prática que o aprendiz recebe uma bolsa de estudos, como ajuda de custo (NASSIF, 2019).

Em outubro de 2020, segundo o relatório Demografia Médica no Brasil 8o,2\% dos egressos do bacharelado em medicina partiram direto para a residência médica. A média de tempo nesta fase é de dois ou três anos, período de grande aprendizado para quem vai assumir grande responsabilidade técnica. Não traz lapso de tempo sem ingressantes, uma vez que o fluxo é dinâmico e com regularidade de novos profissionais incorporando à força de trabalho, levando em consideração a estabilidade no número de concluintes semestralmente. Inclusive no país é a carreira que apresenta menor proporção de vínculos empregatícios após os estudos de terceiro grau (SCHEFFER. et al, 2020, p. 95).

O estudo da medicina é considerado como um dos cursos mais árduos, por requerer do aluno empenho e vigor físico e emocional; as exigências no decorrer da formação levam a se envolverem com a realidade que irão enfrentar na rotina do trabalho, sem romantismo ou devaneios quanto a vivência ocupacional. Desde a graduação o cotidiano é marcado pelo estresse, indicando que nem todo candidato encontra-se preparado para atuar nessa área do conhecimento. O que vem exigindo das instituições de formação acadêmica, maior critério seletivo, que deve apurar além das aptidões sensoriais, intelectuais, as relacionadas à empatia, respeito ao outro, objetividade, responsabilidade e deontologia, só para citar alguns requisitos imprescindíveis para um médico que vai cuidar da saúde das pessoas (BENEVIDES-PEREIRA; GONÇALVES, 2009, p. II). 
No sistema brasileiro de ensino, mesmo diante das alterações nas Diretrizes Curriculares do curso de graduação em medicina, registradas desde 2001 até recentemente em 2019, a metodologia de ensino, ainda se apresenta com base na análise de competências, avaliação de aptidões cognitivas das diversas disciplinas; que ao longo do processo de aprendizagem torna-se, cada vez mais, específicas. O desempenho educacional é medido a partir do uso intensivo das novas tecnologias e conhecimentos que são disponibilizados na literatura especializada, por meio de publicações e leituras de revistas científicas referenciais, com alta exigência de qualidade no segmento científico.

De acordo com Ferreira et al (2019) além da fragilidade dos sistemas de saúde nos cuidados relacionados a determinadas doenças, o atual século expõe a inadequação da formação médica no que diz respeito às principais necessidades de saúde da população. Os autores esclarecem que esses problemas decorrem do processo histórico de elaboração dos currículos, por vezes "descontextualizados, fragmentados e focalizados na técnica" (p. 2). Expõe algumas reformas que contribuíram para a mudança deste cenário como a Relatório Flexner ${ }^{5}$, que determina a formação médica em espaços hospitalares, inovações pedagógicas, como o Problem-Based Learning (PBL) ${ }^{6}$

A partir de metodologias ativas em pequenos grupos de trabalho para a formação de profissionais de saúde, fazendo com que as faculdades de medicina centrem no ensinoaprendizagem no aluno e, preferencialmente, que insiram o conceito social accountability ${ }^{7}$, nos sistemas de saúde que consiste no compromisso de prestação de contas, no acolhimento das questões sociossanitárias das comunidades, regiões ou nações visando o encaminhamento das atividades de ensino, pesquisa e serviço. Ferreira et al (2019, p. 2) destacam "as necessidades de as instituições educacionais estarem engajadas para melhorar o desempenho dos sistemas de saúde, adaptando as competências profissionais essenciais para contextos e cenários específicos”.

\footnotetext{
${ }^{5}$ Em rgro, foi publicado o estudo Medical Education in the United States and Canadá - A Report to the Carnegie Foundation for the Advancement of Teaching, conhecido por Relatório Flexner, é considerado o responsável pela mais importante reforma das escolas médicas de todos os tempos nos EUA, com implicações para a formação médica mundial.

${ }^{6} \mathrm{O}$ PBL é uma metodologia de aprendizagem centrada no ensino autodirigido. Com ela, os estudantes resolvem problemas práticos, sob a supervisão de um tutor, de modo a estimular o pensamento crítico deles.

${ }^{7}$ Subjetivamente é obrigação moral e ética sobre o controle social do trabalho, deve focar permanentemente a responsabilidade de uma pessoa ou organização perante uma outra pessoa, fora de si mesma, por alguma coisa ou por algum tipo de desempenho.
} 
A Educação e a profissão são pilares para o bem-estar das pessoas. Estudos apontam que a formação escolar possibilita ao indivíduo acolhimento psicológico e autoconfiança devido a capacidade de comunicação e interpretação, consequentemente, a sensação de liberdade com amparo nos saberes adquiridos. Ao entesourar conhecimentos o ser humano passa a apresentar um outro tipo de comportamento a começar pela segurança - postura que contribui de forma significativa para a autoestima. Afinal, uma carreira edificada na erudição, metodologicamente estruturada, possibilita às pessoas o enfrentamento da realidade que vão encontrar, rotineiramente, pessoas com saúde debilitada em seu local de trabalho.

$\mathrm{Na}$ atualidade (202I) a independência ocupacional está aliada ao conhecimento e habilidades em outros segmentos relacionados à aprendizagem, mesmo que apenas noções, por exemplo, em Tecnologias da Comunicação e Informação (TIC), idiomas estrangeiros, direito, economia e sociologia. Porque um profissional da saúde deverá estar envolvido com os movimentos sociais comunitários e no voluntariado, porque o país apresenta uma desumana concentração de renda. Sabidamente que o currículo multidisciplinar na graduação, pelo menos, tangencia essas temáticas que levam a um ser mais humano e benevolente com as condições socioeconômicas do outro.

A Educação é condição fundamental no processo de valorização profissional, uma vez que, a remuneração pelo trabalho realizado advém da complexidade que a atividade apresenta e/ou pela singularidade da especialização que a pessoa pode oferecer. $O$ reconhecimento pode vir por meio de retorno financeiro satisfatório, o que motiva o especialista a gradativamente se empenhar na atualização de conhecimentos e dedicação no exercício da função. Essa relação da instrução e laboração está intimamente conectada à Teoria do Capital Humano, que considera,

$$
\begin{aligned}
& \text { que todas as habilidades são inatas ou adquiridas e devem ser aperfeiçoadas por } \\
& \text { meio de ações específicas que levam ao enriquecimento do capital intelectual. } \\
& \text { Desta forma, cada pessoa seria capaz de aumentar seu conhecimento através de } \\
& \text { investimentos voltados à formação educacional e profissional de cada indivíduo. } \\
& \text { Portanto, o aumento do capital humano poderia representar as taxas de } \\
& \text { produtividade do trabalhador, favorecendo o desenvolvimento de um país } \\
& \text { (CABRAL; SILVA; SILVA, 2or6, p.36). }
\end{aligned}
$$

A TCU concebe a ideia de que a trajetória para o desenvolvimento das nações consiste no investimento direcionado ao capital humano. Para isso é fundamental um 
planejamento voltado ao sistema educacional e contemple aprendizagem significativa para a formação humanística, cidadã e crítica. Cabral, Silva e Silva (20r6, p.36) expõe que "neste processo, os professores assumem um papel central, como 'peças fundamentais' para moldar, configurar e ajustar os estudantes ao desenvolvimento econômico. Para isso, seria necessário atender aos princípios de aprendizado, às teorias e à resolução de problemas”.

Ciente de que todo processo formativo, requer a construção do conhecimento a longo prazo, com gradual incorporação dos saberes, apoiado em uma estrutura pedagógica, que possibilita um melhor aproveitamento, a Organização Mundial de Saúde (OMS), desde 1995, vem propondo a reorientação das prioridades e ênfases dos currículos do ensino médico. Porém os resultados amealhados têm sido insuficientes, no que se refere às mudanças na formação médica e às melhorias dos sistemas de saúde. No entanto, com as TICs e outras formas de disseminação da informação, são aliados indispensáveis para a circulação de conteúdos científicos e facilitadores para atualização dos conhecimentos em qualquer área profissional.

Atualmente (2021), como pontua Amaral (2007, p. 3) contempla-se a disparidade entre o discurso dos projetos pedagógicos das IES e a prática, seja na abordagem conteudistas, assim como na metodologia de ensino. A maior carga horária de conhecimentos está na graduação, embora reconheça que a formação médica extrapola essa fase de ensino, os recém saídos da universidade costumam dar continuidade aos estudos:

a) na residência;

b) em cursos de pós-graduação lato sensu na modalidade especialização e,

c) na pós-graduação stricto sensu podendo ser no mestrado e doutorado.

\section{A EMPREGABILIDADE DOS MÉDICOS EM TEMPOS DE NORMALIDADE}

Em novembro de 2020, o Brasil atingiu a marca de 500 mil médicos registrados, sendo que $47.534(9,5 \%)$ tinham mais de um registro profissional (SCHEFFER et al., 2020, p. 35). O comportamento das pessoas que optam pela profissão de médico apresenta um perfil semelhante no que diz respeito à empregabilidade, com carreiras compostas por: a) cargo público (municipal, estadual, distrital ou federal); b) empreendedor individual e, c) situação com menor incidência com vínculo trabalhista na iniciativa privada. Não se trata de irregularidade, mas de uma condição excepcional expressa na Constituição Federal de 
1988 (CF/1988), art. 37, inc. XVI, que esclarece o impedimento na acumulação de cargos públicos, salvo na existência de compatibilidade de horários, “(...) b) a de um cargo de professor com outro, técnico ou científico; c) a de dois cargos ou empregos privativos de profissionais de saúde, com profissões regulamentadas".

A carreira de medicina, cada vez mais, conta com saldo positivo de profissionais por meio de registros nos Conselho Regionais de Medicina (CRM), com ingressos de recém-formados superando as retiradas, seja por aposentadoria, morte ou baixa no registro. Segundo dados do Relatório da Demografia Médica no Brasil, de 2020, indicam Scheffer et al. (2020, p. 39) que a "diferença entre os que entram e os que saem segundo a literatura estrangeira 'saldo de força de trabalho' ou 'estoque profissional', representando assim um número de médicos ativos e, potencialmente, aptos a atuar na profissão ou no sistema de saúde".

Ao ingressar no mercado de trabalho, o médico possui remuneração superior a trabalhadores de outras carreiras com o mesmo número de horas na graduação e similaridade no período de experiência, especialmente, quando estão no início da laboração e sem traquejo. $\mathrm{O}$ mesmo acontece ao ter um vínculo empregatício, o salário é maior se comparado a horas trabalhadas. Trata-se de uma categoria corporativista, conforme descrevem Faria et. al (2018, p. I5) que "atua no sentido de controlar o número de pessoas na atividade, tendo como forte argumento a qualidade dos cursos e a preparação do profissional na universidade". No entanto, o desempenho dos médicos no Exame Nacional de Desempenho dos Estudantes (ENADE) - 2019, alcançou a média de nota 59,5\% do conteúdo ministrado o que é considerada baixíssima pela despretensiosidade do conteúdo cobrado na prova.

O Sistema Único de Saúde (SUS) instituído pela CF/1988, art. 196, considera a "saúde direito de todos e dever do Estado, garantido mediante políticas sociais e econômicas que visem à redução do risco de doença e de outros agravos, com acesso universal e igualitário às ações e serviços para sua promoção, proteção e recuperação". Artigo normatizado pela Lei 8.080/1990, que "dispõe sobre as condições para a promoção, proteção e recuperação da saúde, a organização e o funcionamento dos serviços correspondentes e dá outras providências"; com essa abrangência é um dos maiores sistemas públicos de saúde do mundo. Os estabelecimentos privados podem se organizar 
livremente no país, apenas com autorização para funcionamento e fiscalização estatal; como podem participar do SUS de forma complementar.

No Brasil a profissão de médico tem atratividade e as vagas na graduação são todas preenchidas e as desistências são baixas. No entanto, é evidente a escassez de médicos em diversos municípios. O país apresenta, em média, 2,27 médicos por mil habitantes, porém na região Norte a taxa é de 1,30, representando $43 \%$ menor que a razão média nacional e na região Nordeste, a taxa é de I,69 e desvantagem de 25,5\%. Como solução para resolver a carência pode ser por meio de várias ações políticas, como pondera Scheffer et. al. (2020, p. 48):

a) ampliação da oferta total de vagas nas IES em funcionamento;

b) autorização do MEC para criação de novos cursos;

c) associação das alternativas "a" e "b" e,

d) ter calendário fixo, com pelo menos, dois processos avaliativos anuais do Exame Nacional de Revalidação de Diplomas Médicos Expedidos por Instituição de Educação Superior Estrangeira (Revalida). Uma vez que os critérios deste exame são, infinitamente, mais rigorosos que o ENADE, que não reprova os bacharelandos, mas mede a qualidade do conteúdo ministrado pelas IES.

Em 2020, o Brasil possuía taxa de Io,4 médicos diplomados por Ioo mil habitantes, semelhante à da Grécia (Io,2) e acima das taxas da França (9,5), Estados Unidos (7,8), Canadá $(7,7)$ e Japão $(6,8)$. O país assiste ao aumento desse indicador em razão da política de expansão de cursos e vagas de graduação de Medicina na última década. Especialmente porque existe uma concentração dos profissionais nos grandes centros urbanos, e não estão com predisposição para atuarem em áreas remotas. Muitos brasileiros nunca tiveram a oportunidade de se consultar com um, em especial, os ribeirinhos, povos originários e quilombolas (SCHEFFER et. al, 2020, p.80).

No entanto, a Federação Nacional dos Médicos (FENAM) e o Conselho Federal de Medicina (CFM) vem se posicionando quanto à distribuição no número de profissionais de saúde, conforme a necessidade nas áreas distantes das cidades, dos atuais profissionais a fim de suprir eventuais carências no território nacional. Inclusive indicam políticas públicas de obrigatoriedade de prestação de serviços em locais com falta de assistência para os que cursaram a graduação ou realizam a residência em universidades e 
hospitais públicos ou a graduação ter sido custeada com recursos da sociedade em IES privadas. Porém, não concordam com o aumento do número de médicos e desestimulam a realização do Revalida.

O Brasil é classificado como pertencente ao bloco de nações periféricas - elevada concentração de renda, limitado desenvolvimento humano, baixa qualidade na educação e saúde, infraestrutura em andamento -, que abriga característica de bem-estar social até a extrema pobreza. O que fica evidente com os dados coletados e tabulados pelo IBGE (202I), com informações de 2021, a extensão territorial de $8.514 .876 \mathrm{Km}^{2}$, dividido em 5.570 municípios e abriga uma população estimada de 213,3 milhões. A proporção de unidade da federação e habitantes (hab.) é bastante irregular, conforme Índio do Brasil (202I):

a) 67\% (3.770) dos municípios têm menos de 20 mil hab. e conta com 14,8\% (31,6 milhões) da população; sendo que: i) 30 municípios com menos de I.50o hab. cada e, ii) 4 deles inferior a I.ooo pessoas;

b) $5,8 \%$ (326) dos municípios têm mais de Ioo mil hab. e conta com 57,7\% (I23 milhões) da população; sendo que: i) o,9\% (49) dos municípios com mais de 500 mil hab.; ii) o,3\% (17) deles com população superior a I milhão e, iii) I4 são capitais e concentra 21,9\% (46,7 milhões) da população;

c) as cinco cidades mais populosas são: i) o município de São Paulo é o mais populoso com I2,4 milhões de hab.; ii) em ㄴo lugar, o Rio de Janeiro com 6,8 milhões; iii) em 3으, Brasília com 3,1 milhões; iv) em $4^{\circ}$, Salvador com 2,9 milhões e, v) em 5ํㅜ, Fortaleza com 2,7 milhões.

Mais da metade dos médicos que atuam no Brasil estão concentrados nos grandes centros urbanos A recomendação mínima da OMS é de I (um) atendente por I.ooo habitantes. Contudo, essa razão difere muito entre a capital e outros municípios de um mesmo Estado. Segundo o CFM (2020), existiam 422.00o médicos registrados nos CRM, com menos de 6o anos de idade, em 12/3/2020; porém faltavam cerca de 15.000 profissionais, em 1.864 municípios. A distribuição desordenada pode prejudicar parte da população devido ao aumento da demanda, pela excepcionalidade advinda com a pandemia, especialmente em pronto-atendimento.

A escassez de profissionais de saúde em áreas remotas, como as aldeias indígenas, comunidades quilombolas, populações ribeirinhas, só para citar alguns exemplos, é um obstáculo à universalização do acesso à saúde. O Governo Federal ciente desse crônico 
problema estrutural viabilizou o Projeto Mais Médico para o Brasil (PMMB), disciplinado pela Lei 12.871, de 22/10/2013, possibilitando a contratação de médicos estrangeiros para atuarem em áreas desassistidas e, que os brasileiros não pretendem trabalhar. Foi possível dar sustentáculo na magnitude e em tempo adequado para atender a população em todas as localidades, conforme registraram Oliveira et al. (2015, p. 626):

\begin{abstract}
Em menos de um ano, o PMMB recrutou e alocou 14.462 médicos em 3.785 municípios. A grande inovação do $\mathrm{PMMB}$ se refere à estratégia de chamadas internacionais, quando, além dos 1.846 médicos brasileiros, o programa passou a contar com 12.616 médicos estrangeiros de 49 países participando do programa. Dos médicos estrangeiros que atuam no PMMB, II.429 são médicos cubanos que foram recrutados por meio de uma parceria entre o Ministério da Saúde do Brasil e a Organização Pan-Americana de Saúde e desta última com o Ministério de Salud Pública de Cuba.
\end{abstract}

O Programa Mais Médicos foi introduzido como parte de uma série de medidas para combater as desigualdades de acesso à atenção básica de saúde resolutiva, com o propósito de atender toda a população. A iniciativa garantiu benefícios a 60 milhões de pessoas no Brasil, que em nenhum momento ou quase nunca viram um médico na vida. A política pública de universalização da saúde foi estruturada em três eixos de ação a) investimento na melhoria da infraestrutura da rede de saúde; b) ampliação e reformas educacionais dos cursos de graduação em medicina e residência médica no país e, c) o PMMB (OLIVEIRA at al., 2015, p. 627).

No entanto, o programa durou apenas cinco anos, em vídeos gravados antes de ser eleito, dirigidos aos estudantes de medicina, o presidenciável Jair Bolsonaro prometia a saída dos médicos estrangeiros que atuavam no PMMB. Por exemplo, em 17/10/2018, ele disse: "tamo junto. Em 2019, ao lado de vocês, [vou] dar uma canetada mandando I4 mil médicos lá para Cuba. Quem sabe ocupando Guantánamo que está sendo desativada para atender os petistas que vão para lá, tá ok?" (RODRIGUES, JFSP, 2018). Em outro comício sentenciou: "vou dar uma 'canetada' e usar a revalidação de diploma de médicos para "mandar todos esses cubanos de volta para lá'". Para citar mais um texto, "A classe médica será valorizada e os cubanos vocês sabem para onde irão, tá ok?" (RODRIGUES, Poder 36o, 2018).

Com a eleição do presidente Jair Bolsonaro, dias depois, em I4/II/2018, o governo da República de Cuba comunicou ao presidente Michel Temer que iria retirar os profissionais de seu país que estavam participando do PMMB devido às declarações 
“inaceitáveis, ameaçadoras e depreciativas”, proferidas pelo mandatário eleito que tomaria

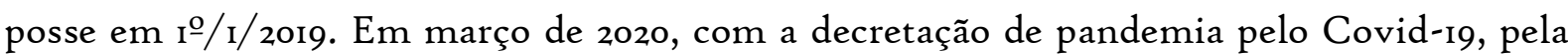
OMS, Attuch (2020) escreveu em um artigo "Os médicos cubanos foram expulsos do Brasil por Bolsonaro, deixou milhões de brasileiros sem atendimento médico para agradar D. Trump e a extrema-direita dos EUA, foram ovacionados ao desembarcar em Roma, na Itália, para atuarem na guerra contra o coronavírus.”

\section{A ATUAÇÃO DOS MÉDICOS BRASILEIROS EM PERÍODO DE PANDEMIA}

Em Iㅇ/I2/2019, ocorreu o primeiro caso de uma doença respiratória aguda causada por vírus, a princípio acreditaram ser uma nova forma de pneumonia. Mas existia um contágio atemorizante, até 10/12/2021, pelo menos 269.293.404 casos da doença foram confirmados em pelo menos igi países, segundo informações da OMS. O histórico da pandemia conforme descrevera Croda e Garcia:

Em 31/12/2019, foi notificada à Organização Mundial da Saúde (OMS) a ocorrência de um surto de pneumonia na cidade de Wuhan, província de Hubei, República Popular da China. Rapidamente, identificou-se o agente etiológico, um novo coronavírus: SARS-COV-2. O surto teve início em um mercado de frutos do mar e animais vivos e, até o momento, o reservatório animal é desconhecido (2020, Editorial, p. I).

Em 22/I/2020, foi discutido por um comitê de emergência, sob a coordenação da OMS, que classificou o evento Covid-ı́ como Emergência de Saúde Pública de Âmbito Internacional (PHEIC), conforme os Regulamentos Internacionais de Saúde (RIS). Em 30/I/2020, a OMS pediu uma ação coordenada pelas autoridades e governos visando combater à doença. $\mathrm{Na}$ primeira semana de fevereiro/2020, o número de mortes causado pelo coronavírus ultrapassou 8oo; no mesmo período em março, os óbitos somaram 3.0oo. Em II/3/2020, a OMS declarou o surto como pandemia (OPAS, 2020).

O que passou a alterar a rotina do mundo, sem planejamento e medidas que fossem confiáveis, já que se tratava de um fato novo para todos, inclusive para os cientistas. A única medida preambular que poderia trazer alguma segurança foi a quarentena (lockdown) visando o distanciamento social, para evitar a propagação do coronavírus. Recomendando o uso de máscara, luvas descartáveis, desinfetantes e cuidados com uso de Equipamentos de Proteção Individual (EPIs) para as pessoas que atuam em 
atividades de primeira necessidade, por exemplo, hospitais, farmácias, supermercados, postos de combustíveis e serviço de tele-entrega.

Com a crise sanitária, todos os profissionais de saúde, que não compõem o grupo de risco, foram convocados para atuarem no atendimento das pessoas em geral e, umas equipes exclusivas para lidar com os infectados pelo Covid-I9, em especial, os que precisam de internação hospitalar. Com sobrecarga de trabalho para os médicos, inclusive as universidades brasileiras adiantaram as formaturas de bacharéis que tinham previsão de concluir o curso no Io semestre/2020, para que pudessem compor equipes de força-tarefa.

O cenário para a atuação profissional é altamente estressante para os médicos com aumento espontâneo da carga horária de trabalho, devido ao momento inesperado em que todos estão envolvidos, com interdependência emergencial àqueles que atuam no segmento da saúde, para atender as pessoas doentes. Além dos riscos que suas próprias vidas ${ }^{8}$ devido à exposição ao coronavírus, podem contaminar as pessoas que têm proximidade, como a família de cada um. Mesmo quando estão usando EPIs, devido ao ambiente insalubre, podem não ser suficientes para evitar o contágio. Porém, está presente a escolha pela profissão, o código de ética, a consciência do dever de cuidado são impulsionadores para o envolvimento físico e psicológico, como o desejo de proporcionar o máximo benefício a todos (FERREIRA et al., 2020, 362).

O adoecimento físico e mental, muitas vezes, pode estar vinculado às demandas no local de trabalho, entre elas as cobranças da chefia, autoexigência ou circunstâncias alheias à vontade de alguém. Podem refletir de maneira negativa reduzindo o desempenho profissional com reflexo na vivência social. Os desdobramentos mais comuns catalogados pelos psicólogos, conforme Lizot e Alves (2021, p. 2-5) são:

a) Esgotamento profissional ou Síndrome de Burnout (SB) ou queima exterior - a pessoa pode sentir insatisfação, cansaço, dúvidas e sentimentos de incapacidade perante sua ocupação, possibilitando o surgimento de culpa por não se doar, inteiramente, ao trabalho da maneira pretendida.

\footnotetext{
${ }^{8}$ Até 29/ro/2021, 893 médicos faleceram no enfrentamento da Covid-rg, segundo o CFM, como o Conselho Federal de Enfermagem (COFEN) publicou, em 19/7/2021, que 838 entre os profissionais de enfermagem perderam a vida pelo mesmo coronavírus. A OMS divulgou em 22/10/2021, que morreram por volta de I80.ooo profissionais de saúde no mundo em decorrência da Covid-ı́.
} 
b) Transtorno de ansiedade - é a previsão e/ou precipitação de uma possível ameaça, algo que não se tem certeza de que pode ou irá acontecer, está classificado entre as doenças psicossomáticas emocionais, com sinais físicos como: náusea, tremor, sudorese, cansaço, dor no peito, tontura, tensão muscular, sensação de falta de ar ou desmaio, respiração ofegante e batimentos cardíacos acelerados.

c) Depressão - conhecida como uma das principais razões de inaptidão do ser humano, os sintomas mais evidentes são: humor mais deprimido (verbalização do sentimento de tristeza ou vazio) perda ou ganho de peso, sonolência excessiva ou insônia, exaustão ou sensação de perda da energia durante vários dias, baixa concentração ou dificuldade para pensar.

d) Estresse - na fase negativa altera o humor, a produtividade, os relacionamentos e a qualidade de vida em geral.

Uma das pesquisas realizadas sobre a saúde física e psicológica dos médicos, especificamente os expostos à pandemia Covid-ı, foi por iniciativa da Escola de Administração de Empresas, em São Paulo, da Fundação Getúlio Vargas (EAESP-FGV), em abril/202I, detectou que $80,2 \%$ dos respondentes sentiram que a sua saúde mental foi afetada negativamente pela pandemia. Ao mesmo tempo, indicaram que as condições de trabalho foram eficientes, na medida do possível, diante de todas as dificuldades em que a sociedade se encontra, como informaram que a distribuição dos EPIs foi satisfatória. Além de considerarem que a sociedade está contribuindo para minimizar a propagação do coronavírus (LOTTA et al., 2020, p. 17-19).

Uma vez que, os profissionais de saúde estão vivenciando uma rotina de trabalho mais intensa, os profissionais indicaram que 61\% deles receberam assistência psicológica e І0,6\% responderam ter sido necessário apoio de psiquiatras. Os laboradores que precisam desses especialistas para auxiliar na compreensão da sua função nesses tempos de surto de coronavírus e suas variantes. Inclusive toda a sociedade está exposta a medos, sofrimentos, angústias e incertezas. Mas é indiscutível a estima que a comunidade credita à classe médica, é sabido que atuando com ética e conhecimento técnico são respeitados pela capacitação e, acolhidos amorosamente como ser humano. Todo ofício tem seus desafios e as inestimáveis contribuições para o bem-estar social (LOTTA et al., 2020, p. 19). 
Conforme destacam Isailã e Hostiuc (2020, p, 427) "O dever de tratar está no centro do debate moral e público sobre a relação médico-paciente em inúmeras epidemias, desde a Grécia Antiga. O dever com perseverança para cumprir a obrigação profissional sem esperar por recompensas.” No caso, muitas vezes o médico terá que intervir, mesmo sem a autorização do paciente, que pode estar em coma, sem capacidade de discernimento, como uma criança pequena. Por isso o código de ética enfatiza quatro direitos e/ou deveres, como: em relação ao paciente, à sociedade, aos colegas e a ele próprio; durante uma pandemia, existe uma obrigação adicional que é o dever de minimizar os riscos de contaminação.

Independente da formalidade ética existem os princípios da bioética como indicam Isailã e Hostiuc (2020, p, 429) que são norteadores em momentos de exceção, como uma pandemia, em que se deve voltar para o pacto social que rege o valor de benevolência que, para os médicos, está no tratamento dos enfermos, com a interdependência entre os profissionais de saúde, os esforços da sociedade em cumprir as recomendações de distanciamento social e uso das EPIs quando precisar estar em ambientes coletivos. O Estado deve estar presente para oferecer a infraestrutura indispensável ao atendimento dos pacientes, informar amplamente sobre as medidas preventivas; como as necessidades de avaliação médica para as demais patologias e, dar suporte financeiro para a população sem recursos suficientes para suprir, minimamente as necessidades das famílias.

\section{METODOLOGIA}

Trata-se de uma investigação de revisão bibliográfica e documental, onde foram consultados fontes secundárias, artigos científicos, livros, dados estatísticos disponibilizados pelos órgãos governamentais, associações de classe, centros de pesquisas e teses no período de 2004 a 2021. Reunindo conhecimentos teóricos para delinear o tema investigado e o fenômeno factual que a sociedade está enfrentando. As bibliotecas virtuais mais utilizadas para a pesquisa foram: Scielo, Google Scholar, a plataforma REDIB e RVBI que é uma agregação de conteúdos de altíssima qualidade científica e acadêmica. 


\section{CONSIDERAÇÕES FINAIS}

Conforme dados disponibilizados na Pesquisa Nacional por Amostra de Domicílios - Contínua (PNAD-C) sob a responsabilidade do Instituto Brasileiro de Geografia e Estatística (IBGE), fonte indispensável para a formulação de estudos visando o desenvolvimento socioeconômico do país. No caso em tela, são resultados acumulados até a posição dezembro/2019, indica 94,552 milhões de brasileiros ocupados, destes 38,806 milhões atuando na informalidade, o que representa $4 \mathrm{I}, 4 \%$ de pessoas que compõem a População Economicamente ativa (PEA) sem nenhum seguro social. Como existe, ainda, um expressivo número de pessoas que desistiu de procurar emprego - pesquisa de desalento -, totalizando 5,7 milhões de trabalhadores (IBGE, 2020).

Após o fim da II Guerra Mundial, economicamente, dividiram os países em dois blocos: industrializados e do terceiro mundo. O Brasil era eminentemente agrário, a partir da década de 1950 começaram os incentivos para o êxodo rural e se tornarem operários, com grandes incentivos após o Golpe Militar de 1964. Em 2020, 84,4\% da população era urbana e $15,6 \%$ moradores em zonas campestres, tornando imprescindível para as pessoas serem remuneradas pela sua mão de obra, direcionando a pauta socioeconômica estatal para a geração de empregos. O Programa de Disseminação das Estatísticas do Trabalho (PDET) sob a responsabilidade do Ministério do Trabalho e Previdência (MTP), série histórica do Seguro Desemprego, consta que 536.844 pessoas solicitaram este benefício, com pagamento em fevereiro/2020 (MTP, 202I).

Os dados coletados não foram impactados pela pandemia do Covid-ı, porque a partir de 12/3/2020, a sociedade passou a enfrentar um momento de exceção por força maior - fatos ou eventos imprevisíveis que não podem ser evitados, mas que provocam consequências ou efeitos para outras pessoas, mas não geram responsabilidade para alguém. Sendo necessários programas emergenciais de geração de renda mínima, para atender as recomendações de isolamento social e, poderem aguardar o cronograma de vacinação determinado pelas autoridades sanitárias. Uma vez que o país não desenvolveu seu imunizante, com isso fica dependente dos fornecedores em base planetária, trata-se de um produto escasso que todos precisam consumir com urgência. 
De acordo com os dados do CFM existem médicos suficientes para atender a sociedade brasileira, em momentos de excepcionalidade, não se pode contar com a força de trabalho dos profissionais que compõem o grupo de risco, porque a atividade exige envolvimento físico com alta possibilidade de contágio. O que se verifica é a concentração da disponibilização de mão de obra em centros urbanos, deixando desassistida uma grande parcela da população que reside em pequenas cidades, no meio rural, comunidades tradicionais como: os Indígenas, Quilombolas, Caboclos, Caiçaras, Extrativistas, Jangadeiros, Pescadores, Ribeirinhos e Seringueiros, só para citar as mais conhecidas.

Porém, deve ter acompanhamento popular na atual política universitária, que está tendo drástica redução dos recursos previstos nos orçamentos públicos, afetando indistintamente os cursos de graduação, pós-graduação lato sensu e stricto sensu e, a estrutura física e de recursos humanos para as pesquisas. Em alguns anos pode haver a falta de profissionais médicos, no Brasil, devido a redução dos recursos financeiros para as IES públicas; corte no número de bolsas de estudos nas IES privadas e, vagas de residência médica. Como a força de trabalho deve reduzir por meio da supressão de concursos públicos para preenchimento de cargos para médicos nas três esferas administrativas federadas (municípios, estados-membros, Distrito Federal e União). Desde o ano de 2016, existe uma séria crise política, com direcionamento para o modelo de política econômica neoliberal (Estado mínimo), com retração no crescimento econômico e recessão após o início da pandemia Covid-ı.

Os hábitos da sociedade brasileira estão inseridos no mercado global, o que requer uma política econômica clara e de Estado, com uma equipe de técnicos altamente qualificados para acompanharem persistentemente os fatores de produção para reduzir desequilíbrio e recessões que impactam todos, a começar pelo desemprego. No caso dos médicos, a longo prazo, pode ocorrer redução no número de pacientes na rede privada, tanto os que optam por adquirirem planos de saúde, como os que fazem pagamentos diretos aos profissionais, clínicas e hospitais; inclusive refrear o valor do Coeficiente de Honorários $(\mathrm{CH})$. Por outro lado, a demanda por serviços de saúde no SUS aumenta e sobrecarrega o sistema que é de atendimento universal, como pode comprometer os diagnósticos com a obsolescência dos equipamentos e falta de investimentos em aparelhos de ponta, colocando em risco a indicação do acertado tratamento. 
Diante da realidade, em 13/12/2021, o país contabiliza 616.94I mortos, 22.187.349 de pessoas contaminadas Covid-I9, devidamente confirmados por meio de exames, porque a subnotificação é grande; a população imunizada por meio de vacinas é de $65,3 \%$. No entanto, a circulação do coronavírus continua altíssima no país, inclusive com o aparecimento de novas variantes. O retorno a uma possível normalidade não está no horizonte, em especial para a retomada do crescimento econômico, porque a quarentena durou quinze dias no início, porque na Páscoa de 2020, os comércios nas cidades já estavam abertos e continuam até a presente data; as estatísticas não indicam geração de empregos e renda para os trabalhadores. O mais impactante é que a fome avança e já atingiu 19,I milhões de brasileiros nos últimos dois anos e com a pandemia cerca de iı6,8 milhões estão em algum dos graus (leve, moderado ou grave) de insegurança alimentar (REDE PENSSAN, 2021, p. 10).

Verificou-se que, a classe dos médicos foi largamente afetada física e psicologicamente com a exposição e maior possibilidade de serem contaminados pelo Covid-ı, mesmo assim estão envolvidos com a restauração da saúde de todas as pessoas, sejam acometidos pelo coronavírus ou outras doenças que exijam a intervenção ou o acompanhamento médico. Mesmo o Estado brasileiro estando desestruturado foi mantido, precariamente o pacto social, com orçamento de guerra para gastos com produtos e serviços destinados ao combate da pandemia. Renda mínima para as pessoas que não encontram ocupação remunerada, com descontinuidade de pagamentos em alguns meses e valores, muitas vezes, insignificantes, mas com previsão de parcelas até dezembro/202I.

Infelizmente, a sociedade não cumpriu o seu pacto, com pequena parcela obedecendo a quarentena, condizente com as determinações de cada prefeito ou em conjunto com os governadores dos estados-membro em que pertencem. Mesmo recebendo o auxílio emergencial as pessoas voltaram às suas atividades, usando transportes públicos e as lojas abertas com normalidade, contribuindo sobremaneira para manteve a circulação do vírus. Tudo indica que as autoridades públicas não conseguiram convencer os empresários da necessidade de preservar o bem maior: a vida de todos.

O retorno à normalidade, mesmo contra a indicação das autoridades sanitárias, contou com incondicional apoio do Presidente da República e apoio de parte da sociedade 
que popularmente são chamados de negacionistas ${ }^{9}$ - quando ocorre a hesitação às vacinas e descrédito na ciência e na história. Segundo o ocupante do mais alto posto administrativo do país o coronavírus causava uma "gripezinha" e, morrer faz parte do ciclo natural da vida. Como é adepto de um contingente de pessoas ao redor do mundo que participam de um movimento antivacina, só no Brasil, a estimativa é de $25 \%$ dos adultos contrários a qualquer tipo de vacinação (PENAFORTE, 202ı, p. 9).

Neste artigo foi evidenciada a categoria dos médicos, sendo possível constatar que prosseguem cuidando da saúde da comunidade, mesmo sabedores de estão em meio a uma patologia altamente contagiosa. Como foi averiguado a pressão psicológica pode ter desdobramentos desfavoráveis, por meio de acometimento à saúde física e mental dos profissionais de saúde. Mesmo assim, seguem cumprindo o pacto social do cuidado e da responsabilidade com o bem comum. Especialmente, porque podem contar com uma estrutura que vem sendo delineada desde 1974, com o INAMPS, e a universalização veio em I990, com a marca SUS.

\section{REFERÊNCIAS}

AMARAL, Jorge Luiz do, (2007). Duzentos anos de ensino médico no Brasil. [Tese de Doutorado, apresentada no Programa de Pós-graduação em Saúde Coletiva da Universidade do Estado do Rio de Janeiro (UERJ)]. Rio de Janeiro, 2007, $207 \mathrm{f}$. Disponível em: http://www.bdtd.uerj.br/handle/I/4592. Acesso em: I3 dez. 2021.

ATTUCH, Leonardo. Expulsos do Brasil por Bolsonaro, médicos cubanos são aplaudidos ao desembarcar na Itália. Brasil 247. São Paulo, 22 mar. 2020. Disponível em: https://www.brasil247.com/mundo/expulsos-do-brasil-por-bolsonaro-medicos-cubanossao-aplaudidos-ao-desembarcar-na-italia. Acesso em: 29 ago. 202I.

BENEVIDES-PEREIRA, Ana Maria T.; GONÇALVES, Maria Bernadete. Transtornos emocionais e a formação em Medicina: um estudo longitudinal. RBEM: Revista Brasileira de Educação Médica - Universidade Estadual de Maringá (UEM). Maringá-PR, 33(I): Io23, mar. 2009. Disponível em: https://doi.org/10.1590/Soroo-55022009000100003. Acesso em: Io out. 2021.

\footnotetext{
9 A teoria negacionista sintetiza na boa retórica e capacidade argumentativa capaz de convencer e enganar outras pessoas. Ratificando teses conspiratórias - evoca a falsa ideia de que há uma verdade oculta que não é divulgada por haver por trás dela uma grande conjuração internacional. Manipulam informações, em especial, a descontextualização de algumas delas, a supressão de outras, e até mesmo, o falseamento claro de dados. A manobra se dá pela utilização de falsos especialistas (charlatães). Um exemplo conhecido é negarem a existência do Holocausto mesmo com as evidências documentais do genocídio de judeus (PENAFORTE, 202I, p. 8).
} 
BRASIL. Constituição da República Federativa do Brasil (1988), promulgada em Brasília, em 5 out. 5 1988. Disponível em: http://www.planalto.gov.br/ccivil_03/constituicao/constituicao.htm. Acesso em: I2 out. 2021.

Lei 8.080, de 19 de setembro de 1990. Dispõe sobre as condições para a promoção, proteção e recuperação da saúde, a organização e o funcionamento dos serviços correspondentes e dá outras providências. Disponível em: http://www.planalto.gov.br/ccivil_03/leis/18o8o.htm. Acesso em: I2 out. 202I.

. Lei 12.871, de 22 de outubro de 2013. Institui o Programa Mais Médicos, altera as Leis no 8.745, de 9 de dezembro de 1993, e no 6.932, de 7 de julho de 1981, e dá outras providências. Disponível em: http://www.planalto.gov.br/ccivil_03/_Ato2ori2014/2013/Lei/Li2871.htm. Acesso em: Io out. 2021.

CABRAL, Antônio; SILVA, Claudia Luciene de Melo; SILVA, Lamara Fabia Lucena. Teoria do capital humano, educação, desenvolvimento econômico e suas implicações na formação de professores. Revista Principia - Divulgação Científica e Tecnológica do Instituto Federal da Paraíba. João Pessoa, n 32, p. 35-4I, dez. 20I6. Disponível em: https://periodicos.ifpb.edu.br. Acesso em: I5 nov. 2021.

CFM - Conselho Federal de Medicina. Linha de frente: 422 mil médicos podem atuar contra Covid-19. Jornal Medicina: CFM. Brasília, a. XXXV, n. 303, p. I-12. 26 jun. 2020. Disponível em: https://portal.cfm.org.br/noticias/nova-edicao-do-jornal-medicinamostra-que-ha-medicos-suficientes-para-atender-a-populacao-durante-a-pandemia-decovid-19/. Acesso em: I5 nov. 2021.

CRODA, Julio Henrique Rosa; GARCIA, Leila Posenato. Resposta imediata da vigilância em saúde à epidemia da Covid-ı9. Revista Epidemiologia e Serviço de Saúde - da Secretaria de Vigilância em Saúde, do Ministério da Saúde do Brasil - Editorial. 29 (I): I4, 23 mar. 2020. Disponível em: https://doi.org/10.5123/Si679-49742020000100021. Acesso em: I5 nov. 2021.

FARIA, Mateus Aparecido de; ROCHA, Cristianne Maria Famer; BRITES, Liara Saldanha; MACHADO, Angela Maria Grando; SANTOS, Claiton Agnaldo Ribeiro; CECHINEL, Neuza de Freitas Raupp; MATIVI, Rossana dos Santos Rocha. Programa Mais Médicos e sua repercussão na mídia: o que informar e para quem? RECIIS - Revista Eletrônica de Comunicação, Informação e Inovação em Saúde, da Fundação Oswaldo Cruz (FIOCRUZ). Rio de Janeiro, I2(I):I4-25. jan.-mar. 2018. e-ISSN 198I-6278. Disponível em: http://dx.doi.org/I0.29397/reciis.vi2ir.1263. Acesso em: I2 out. 2021.

FERREIRA, Marcelo José Monteiro; RIBEIRO, Kelen Gomes; ALMEIDA, Magda Moura de; SOUSA, Maria do Socorro; RIBEIRO, Marco Túlio Aguiar Mourão; MACHADO, Márcia Maria Tavares; KERR, Ligia Regina Franco Sansigolo. Novas Diretrizes Curriculares Nacionais para os cursos de Medicina: oportunidades para ressignificar a 
formação. Interfaces: comunicação, saúde e educação (Botucatu) 23 (Supl. I), p. I-15, 2019. Disponível em: https://doi.org/10.1590/Interface.170920. Acesso em: 12 dez. 2021.

FERREIRA, Maria Amélia; CARVALHO FILHO, Marco Antonio; FRANCO, Giuliani dos Santos; FRANCO, Renato Soleiman. Profissionalismo médico e o contrato social: reflexões acerca da pandemia de Covid-ı. Revista Científica da Ordem dos Médicos ACTA Médica Portuguesa. Lisboa, 33(6), p. 362-364, jun. 2020, Disponível em: http://doi.org;io.20344/amp.13769. Acesso em: 7 set. 2021.

IBGE - Instituto Brasileiro de Geografia e Estatística. PNAD-C - Pesquisa Nacional por Amostra de Domicílios Contínua, posição dez. 2020. PNAD Contínua: taxa de desocupação é de II,O\% e taxa de subutilização é de 23,0\% no trimestre encerrado em dezembro. Agência IBGE - Estatísticas Sociais, divulgação em 31 jan. 2020. Disponível em: https://agenciadenoticias.ibge.gov.br/agencia-sala-de-imprensa/2013-agencia-denoticias/releases/26740-pnad-continua-taxa-de-desocupacao-e-de-II-o-e-taxa-desubutilizacao-e-de-23-o-no-trimestre-encerrado-em-dezembro. Acesso em: I2 out. 202I.

. Portaria IBGE-PR 268, de 26/8/2021. Resolve divulgar as estimativas da População para Estado e Municípios com data de referência em Io de julho de 2021, constantes da relação anexa, para os fins previstos no inciso VI do Art. Io da Lei no 8.443, de I6 de julho de 1992. DOU - Diário Oficial da União, Brasília, 27/8/2021, Edição I63, Seção I, pág. 6o. Disponível em: https://www.in.gov.br/en/web/dou/-/portaria-n-pr-268-de-26-de-agostode-2021-341037196. Acesso em: io out. 2021.

ÍNDIO DO BRASIL, Cristina. Brasil tem 49 municípios com mais de 500 mil habitantes: juntas, essas cidades representam 31,9\% da população brasileira. Agência Brasil, publicado em 27 ago. 2021, Rio de Janeiro. Disponível em: https://agenciabrasil.ebc.com.br/geral/noticia/2021-08/brasil-tem-49-municipios-commais-de-500-mil-habitantes. Acesso em: ro out. 2021.

INEP - Instituto Nacional de Estudos e Pesquisas Educacionais Anísio Teixeira. Censo da Educação Superior: Sinopse Estatística da Educação Superior 2019. Brasília: Inep, 2020. Disponível em: http://portal.inep.gov.br/basica-censo-escolar-sinopse-sinopse. Acesso em: 9 dez. 202I.

ISAILÃ, Oana-Maria; HOSTIUC, Sorin. O dever de tratar no contexto da pandemia de Covid-ı. Revista Bioética. Brasília, 28(3): 426-431, jul. / set. 2020. SSN 1983-8042. Disponível em: Doi: 10.1590/1983-80422020283403. Acesso em: 30 nov. 2021.

LIZOT, Paula Cristina; ALVES, Cássia Ferreira. (2021). A relação entre síndrome de burnout, stress, depressão, ansiedade e qualidade de vida de médicos. Revista Universo Psi publicação do Curso de Psicologia das Faculdades Integradas da Taquara (FACCAT). Taquara-RS, 2(I): I-I6, 2021. Disponível em: https://seer.faccat.br. Acesso em: 13 dez. 2021.

LOTTA, Gabriela; FERNANDES, Michelle; MAGRI, Giordano; MELLO, Claudio Aliberti de Campos; CORRÊA, Marcela Garcia; ROCHA, Mariela Campos; TAMAKI, 
Eduardo Ryo; SCHALL, Brunah; PIMENTA, Denise Nacif. A pandemia de Covid-ra e (os)as profissionais de saúde pública no Brasil - $4^{\underline{a}}$ fase. Núcleo de Estudos da Burocracia (NEB), da Escola de Administração de Empresas de São Paulo (EAESP), da Fundação Getúlio Vargas (FGV). Nota Técnica, p. I-32, abr. 2021. Disponível em: https://portal.fiocruz.br. Acesso em: 30 nov. 2021

MEC - Ministério da Educação. SiSU - Sistema de Seleção Unificada. SiSU ofertará mais de 290 mil vagas na seleção do Io semestre de 202I. Brasília, 8 mar. 202I. Disponível em: https://www.gov.br/pt-br/noticias/educacao-e-pesquisa/202I/o3/sisu-ofertara-mais-de209-mil-vagas-na-selecao-do-ıo-semestre-de-2021. Acesso em: 9 dez. 202I.

MTP - Ministério do Trabalho e Previdência. PDET - Programa de Disseminação das Estatísticas do Trabalho. Seguro-desemprego: séries históricas do seguro-desemprego 2000 a 2021. Brasília, I2 nov. 2021. Disponível em: http://pdet.mte.gov.br/component/content/article?id=I778. Acesso em: I5 nov. 202I.

NASSIF, Antonio Celso Nunes (Coord.). Estatísticas nacionais dos cursos de medicina 2019. Escolas Médicas do Brasil (EMB). Disponível em: https://www.escolasmedicas.com.br/estatisticas-nacionais.php. Acesso em: I2 dez. 2021.

OLIVEIRA, Felipe Proenço; VANNI, Tazio; PINTO, Hêider Aurélio; SANTOS, Jerzey Timoteo Ribeiro dos; FIGUEIREDO, Alexandre Medeiros de; ARAÚJO, Sidclei Queiroga de; MATOS, Mateus Falcão Martins; CYRINO, Eliana Goldfarb. Mais médicos: um programa brasileiro em uma perspectiva internacional. Interface: comunicação, Saúde e Educação (Botucatu). 19(54): 623-634, jul.-set. 2015. Disponível em: https://doi.org/10.1590/1807-57622014.1142. Acesso em: 13 out. 2021.

OPAS - Organização Pan-Americana de Saúde. A OMS afirma que COVID-ı́ é agora caracterizada como pandemia. Brasília, II mar. 2020. Disponível em: https://www.paho.org/pt/news/II-3-2020-who-characterizes-covid-I9-pandemic. Acesso em: I2 dez. 202I.

PENAFORTE, Thais Rodrigues. $O$ negacionismo enquanto política: o debate da cloroquina em uma comissão parlamentar. Cadernos de Saúde Pública - Escola Nacional de Saúde Pública Sergio Arouca, da Fundação Osvaldo Cruz. Rio de Janeiro, 37(7): I-13, 25 jun. 2021. Disponível em: https://doi.org/10.1590/oro2-31IXooo23021. Acesso em: 3 dez. 2021.

REDE PENSSAN - Rede Brasileira de Pesquisa em Soberania e Segurança Alimentar e Nutricional. Insegurança alimentar e Covid-ı no Brasil. Rio de Janeiro, 202ı, 66 p. ISBN 9786587504 I9 3. Disponível em: https://pesquisassan.net.br/olheparaafome/. Acesso em: I3 dez. 2021.

REZENDE, Joffre Marcondes de. À sombra de plátano: crônicas de história da medicina. São Paulo: Editora Unifesp, 2009. 408 p. (História da Medicina; vol. 2). ISBN: 978-8561673-10-9. 
RODRIGUES, Artur. Antes da eleição, Bolsonaro falou em mandar cubanos embora com 'canetada'. Jornal Folha de São Paulo. Publicação de 15 nov. 2018. Disponível em: https://wwwi.folha.uol.com.br/cotidiano/2018/II/antes-da-eleicao-bolsonaro-falou-emmandar-cubanos-embora-com-canetada.shtml. Acesso em: 29 ago. 202I.

RODRIGUES, Fernando. Em campanha, Bolsonaro citou 'canetada' para tirar médicos cubanos do país: país rompeu parceria nesta $4^{\underline{a}}$ feira. Poder 360 . Publicação do diretor de redação, Brasília, em 17 nov. 2018. Disponível em: https://www.poder36o.com.br/governo/em-campanha-bolsonaro-citou-canetada-paratirar-medicos-cubanos-do-pais/. Acesso em: 29 ago. 202I.

SCHEFFER, Mário (Coord.); CASSENOTE, Alex; GUERRA, Alexandre; GUILLOUX, Aline Gil Alves; BRANDÃO, Ana Pérola Drulla; MIOTTO, Bruno Alonso; ALMEIDA, Cristiane de Jesus; GOMES, Jackeline Oliveira; MIOTTO, Renata Alonso. Demografia Médica no Brasil 2020. São Paulo: Faculdade de Medicina da Universidade de São Paulo (FMUSP), Conselho Federal de Medicina (CFM), 312 p. ISBN:978-65-00-12370-8.

SCHULTZ, Theodore W. O valor econômico da educação. Trad. P.S. Weneck. Rio de Janeiro: Zahar Editores, 1967, Ior p. 